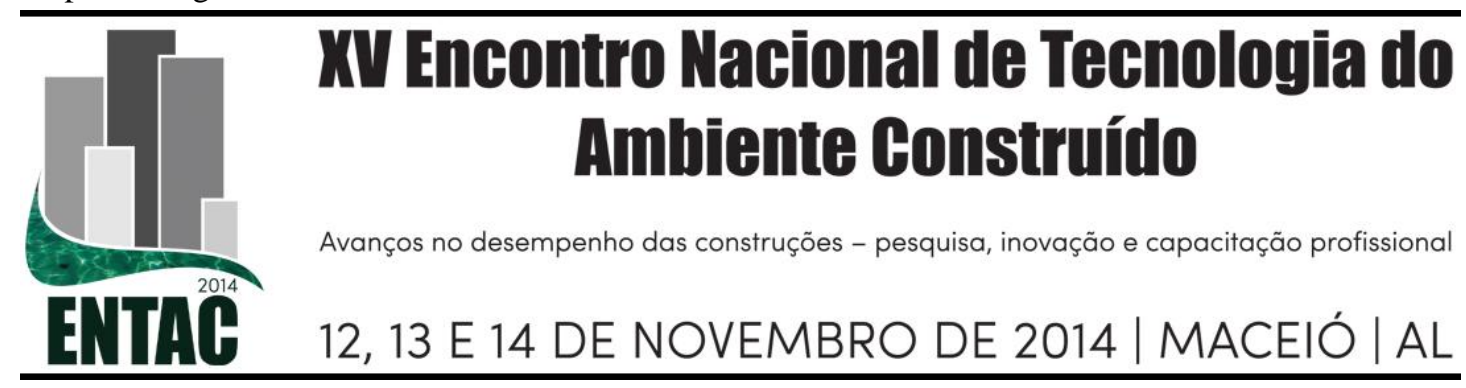

\title{
DESIGN PARA A MANUTENIBILIDADE NO USO DA FERRAMENTA GSP NOS SERVIÇOS PREDIAIS INDUSTRIAIS
}

\author{
SILVA, Vanessa Cristine \\ Universidade Federal de Minas Gerais, e-mail: vanessacristinesilva@gmail.
}

\begin{abstract}
RESUMO
Partindo da importância da manutenção civil, pretende-se mostrar neste estudo o processo de gerenciamento de solução de problemas GSP, como sendo uma ferramenta de aplicação eficiente, adequada aos sistemas inteligentes, atendendo à satisfação dos clientes, ao reconhecimento do mercado, e alcançando padrões de alta qualidade e produtividade, dentro de um complexo industrial. As características singulares do processo de manutenção predial são pouco abordadas nas obras existentes, portanto este trabalho é apenas uma amostragem de como os sistemas de manutenção predial podem ser desenvolvidos por acompanhamento de uma ferramenta de gestão. As necessidades de constantes adequações na estrutura física de instalações, por motivo ergonômico ou para facilitar o dia a dia das pessoas, são situações que fazem parte da rotina de um gestor de manutenção civil predial e que, obviamente, se não houver uma gestão eficiente de toda essa demanda, diversos fatores podem ocorrer como: indisponibilidade nas instalações, riscos de acidentes, usuários insatisfeitos, condições físicas que irão impactar em improdutividade, custos altos e desnecessários e até mesmo a desvalorização do empreendimento.
\end{abstract}

Palavras-chave: Manutenção, gestão predial, processo produtivo.

\begin{abstract}
Taking into account the importance of maintaining civil, this study aims to show the process of troubleshooting management GSP as a tool of efficient application, appropriate to the intelligent systems, taking into account the satisfaction of customers and the recognition of the market, and achieving high standards of quality and productivity, within an industrial complex. The unique features of the process of building maintenance are barely addressed in existing works, so this job is just a sampling of how the building maintenance systems can be developed for monitoring of a management tool. The need for constant adjustments in physical structure of facilities, by reason or ergonomic to facilitate the everyday life of the people, these are situations that are part of the routine of a civil maintenance and property manager that, obviously, if there is an efficient management of all this demand, several factors can occur as: unavailability on the premises, risks of accidents, disgruntled users, physical conditions that will impact in lack of productivity, high costs and unnecessary and even the devaluation of the enterprise.
\end{abstract}

Keywords: Maintenance, building management, production process.

\section{INTRODUÇÃ̃O}

Conforme publicado em 1994, na NBR 5.462, a manutenção é definida como a combinação em ações técnicas e administrativas, incluindo as de supervisão, destinadas a manter ou relocar um item em um estado no qual possa desempenhar uma função requerida, num nível de desempenho exigido. Para tanto, as atividades de manutenção existem para manter sobre controle a degradação dos equipamentos e das instalações, causada pelo seu desgaste natural e pelo uso. Essa degradação se manifesta de diversas formas, desde a aparência externa ruim dos equipamentos até as perdas de desempenho e paradas de produção, fabricação de produtos de má qualidade e poluição ambiental. Já 
a norma inglesa, BS-3811/1993, define manutenção como a combinação de qualquer ação para reter um item ou restaurá-lo, de acordo com um padrão aceitável.

A manutenção civil predial é, de fato, um tema pouco abordado nas literaturas técnicas. Percebe-se no setor uma carência de modelo de qualidade eficiente, seja por questões culturais ou por se pensar que serão apenas mais despesas e que não irão agregar valor ao sistema predial. A falta de uma organização de trabalho que tenha como base o processo simultâneo pode trazer consequências desagradáveis aos usuários como: indisponibilidade dos complexos prediais, baixa confiabilidade e o aumento de riscos das edificações. É importante destacar que a manutenção é uma atividade participante do processo produtivo e não uma mera atividade secundária de apoio. Portanto, deve haver a consciência da necessidade da empresa de maximizar lucros e minimizar custos. Este trabalho procura apresentar uma reestruturação das atividades de manutenção predial de rotina de forma sistêmica.

\subsection{Objetivo}

Este artigo busca apontar quais as ferramentas que podem ser adotadas para resolver problemas nos serviços da manutenção predial, demonstrando de forma sistêmica o uso do processo de gerenciamento do GSP - Grupo de Soluções de Problemas, através de quatro etapas de trabalho com o envolvimento de toda a equipe.

\subsection{Justificativa}

Segundo Ishikawa (1984), a manutenção tem que ter a instalação adequada e sempre disponível às necessidades da empresa, fazendo uso dos conceitos e métodos de qualidade no exercício de suas atividades, atendendo, assim, às necessidades de seu cliente através da produção. Além disso, a qualidade da manutenção está ligada a procedimentos de combate às falhas e suas causas, ao bom entrosamento da equipe, ao aumento da produtividade e à definição dos procedimentos da organização. Para o autor, várias ferramentas gerenciais relacionam-se às atividades dos responsáveis pela manutenção, tais como: CCQ (Circulo de Controle de Qualidade), TPM (Manutenção Produtiva Total), GQT (Gestão de Qualidade Total), PDCA (Método de Controle de Processos), MASP (Método de Analise e Solução de Problemas), FMEA (Análise de Modo de Falha), RCFA (Análise de Causa Raiz de Falha), MCC (Manutenção Centrada em Confiabilidade), Análise de Pareto, CEP (Controle Estatístico do Processo), Programa "5S", 5W1H, Método dos Porquês, sendo importante saber que são simplesmente ferramentas e sua simples utilização não significa exatamente a obtenção de bons resultados. Por outro lado, o uso adequado dessas ferramentas pode levar a excelentes resultados, que podem contribuir para a qualidade na manutenção. Neste estudo, o GSP é um procedimento uniforme e padrão, através do qual as reais causas dos problemas são reconhecidas e eliminadas de forma duradoura. Para a solução desses problemas, são necessários o envolvimento e o comprometimento de todos e a resolução definitiva dos problemas. Para que se possa realizar melhor o trabalho do dia a dia, a solução de problemas é uma ferramenta que facilita a resolução dos problemas crônicos existentes nas áreas de manutenção. 


\section{METODOLOGIA}

Para se desenvolver este trabalho, foram utilizadas as pesquisas bibliográficas, que apresentam conceitos, regras e diretrizes de um dado contexto para um projeto de viabilidade na implantação de uma ferramenta de gestão num complexo industrial no estado de Minas Gerais, e o estudo de caso, este, a mola propulsora desta etapa do trabalho. Com o objetivo de atender à necessidade de melhoria na produção e na redução de custos e desperdícios para o setor de manutenção, este projeto envolveu um grupo de engenheiros, analistas e técnicos, coordenados pelo supervisor de manutenção, para estabelecer indicadores, definir as metas e os planos de ação, através de várias sessões de brainstorming ${ }^{l}$. Esses indicadores foram baseados em quatro etapas: 1 Identificação; 2 - Observação; 3 - Análise; 4 - Plano de ação; 5 - Ação; 6 Verificação; 7 - Padronização. Com base nas informações coletadas, cada etapa foi realizada através da criação de uma série de procedimentos, entre os quais a fiscalização e elaboração de padrões da rotina da manutenção civil predial. Cada indicador terá definida a meta que deverá cumprir a cada 30 dias, cabendo ao supervisor analisar se a ação é consistente e propõe melhorias nos processos.

\section{ANÁLISE E RESULTADO DE DADOS}

\subsection{Identificação do problema}

Os principais pontos levantados como barreiras referem-se ao baixo número de horas produtivas no contrato de manutenção civil predial e no atraso na entrega dos serviços. Uma vez apurados dados quantitativos, os valores contabilizados são: média de horas produtivas diárias por pessoa dos meses de setembro de 2009 a fevereiro de 2010 de 3,73 horas/mês, tendo como meta o valor meta de 4,29 horas/mês; número de ordens de serviço atendidas no período totalizando 894, para um efetivo de mão de obra contratado de 41 executantes e com 24 equipamentos no contrato.

\subsection{Observação do problema}

Na observação é necessário investigar os aspectos específicos do problema sob vários pontos de vista, por exemplo: a. Tempo - os resultados são diferentes de manhã, à tarde, à noite, às segundas-feiras e feriados; b. Local - deve-se levar em consideração as condições climáticas, unidade relativa do ar, temperatura do ambiente e condições dos instrumentos de medição. Foram utilizadas nesta etapa de observação as ferramentas de qualidade: cartas de controle e o gráfico de pareto.

\subsubsection{Canteiro da contratada - layout inadequado}

Neste ambiente foram identificados barreiras e fenômenos ocorridos de algumas especialidades rotineiras, tais como: a perda de tempo na distribuição de ferramentas e controle deficiente de materiais; área de serralheria incompatível com a necessidade; perda de tempo e controle deficiente nos serviços de vidraçaria em função da localização.

\footnotetext{
${ }^{1}$ O brainstorming (tempestades de ideias sem críticas e julgamento) é uma ferramenta associada à criatividade e seu uso se justifica na fase de planejamento na busca de soluções. Através de um grupo de pessoas, cria-se uma tempestade de ideias acerca do assunto tratado, objetivando a identificação de problemas e questionamento de causas ou a análise da relação causa e efeito.
} 


\subsubsection{Planejamento e programação dos serviços}

A etapa de planejamento trata-se de uma abordagem sistêmica para integrar simultaneamente todos os processos relacionados. Para tanto se percebe a ausência e a deficiência no planejamento das ordens de serviços - cronograma mensal; a ausência de controle e acompanhamento sistemático da programação geral dos serviços; o formulário de apropriação de horas/serviços inadequado.

\subsubsection{Equipamentos}

O objetivo deste passo é fazer com que os operadores utilizem os padrões com a máxima efetividade. Nesse contexto, a utilização de equipamentos é baixa, além da quantidade de ferramentas de serralheria ser insuficiente, considerando também a indisponibilidade de equipamentos e veículos.

\subsubsection{Efetivos de mão de obra}

Esta abordagem mobiliza os executantes desde o início até o fim do ciclo do processo, incluindo qualidade, custos, prazos e necessidades dos clientes. Conforme observado em campo, o efetivo se mostrou insuficiente e inadequado para atender à demanda de serviços e ao elevado índice de absenteísmo e turn-over.

\subsubsection{Materiais}

Observa-se o controle deficiente de materiais requisitados para o almoxarifado; o desperdício (sobra de obra) não é reaproveitado; há demora na reposição do material e entrega em local indevido.

\subsubsection{Frentes de serviço}

Neste contexto, inspeções avaliam a situação do processo no contexto do ambiente, analisando equipamentos, materiais e operadores na rotina da manutenção. Neste passo o objetivo é combater a paralisação de atividades antes do horário previsto, evitar a perda de horas produtivas nas obras devido ao tempo de deslocamento de um local para outro; a baixa inovação de materiais e metodologias de execução; o baixo nível de qualificação e treinamento ao pessoal de obra; sobrecarga de atividades para o líder e baixa autonomia ao líder de campo; falta de planejamento de atividades que requerem permissões de trabalho.

\subsection{Análise}

O envolvimento de todas as pessoas é a principal contribuição na identificação das causas. As reuniões de brainstorming são participativas, pois é na base dos resultados das experiências que será confirmada ou não a existência de relação entre o problema e as causas mais prováveis. Uma ferramenta da qualidade importante utilizada nesta etapa é a Matriz GUT. Sua vantagem na gestão de problemas é auxiliar o gestor a avaliar de forma quantitativa a resolução dos problemas, objetivando priorizar possíveis ações corretivas e preventivas para alcançar um resultado parcial ou total da eliminação do problema. O início de partida para montagem da Matriz GUT é listar as causas contemplando os aspectos e os problemas a serem analisados. Em seguida, será atribuída uma nota para cada problema listado, dentro de três aspectos: gravidade, urgência e tendência. A gravidade representa o impacto do problema analisado sobre alguns aspectos tais como, tarefas, pessoas, resultados, processos e organizações. Ao 
que se refere, o aspecto urgência significa a necessidade disponível de tempo e prazo para resolver o problema. Na tendência, fica evidenciado o potencial do problema, a probabilidade do problema se tornar maior com o passar do tempo. É a avaliação da tendência de crescimento, redução ou desaparecimento do problema. A regra de cálculo que determinará o grau de prioridade do problema é feita pela multiplicação dos valores de cada problema seria $(\mathrm{G}) \times(\mathrm{U}) \times(\mathrm{T})$, sendo o produto da Matriz GUT $=125$.

Quadro 1 - Análise das causas através da Matriz GUT

\begin{tabular}{|c|c|c|c|c|}
\hline \multirow{2}{*}{ Causa } & \multicolumn{3}{c|}{ Gravidade Urgência Tendência } \\
\cline { 2 - 5 } & Muito & Médio & Pouco & Total \\
\hline $\begin{array}{c}\text { Acompanhamento deficiente de materiais no } \\
\text { almoxarifado da contratada }\end{array}$ & $(\mathrm{X})$ & & & 125 \\
\hline Alto índice Absenteísmo e Turn-over & $(\mathrm{X})$ & & & 125 \\
\hline Baixo nível reciclagem profissional e treinamentos & $(\mathrm{X})$ & & & 125 \\
\hline $\begin{array}{c}\text { Grande perda de tempo no deslocamento para } \\
\text { canteiro/vestiário e obras }\end{array}$ & $(\mathrm{X})$ & & & 125 \\
\hline Planejamento deficiente de materiais & $(\mathrm{X})$ & & & 125 \\
\hline Processo de compras/suprimentos & $(\mathrm{X})$ & & & 125 \\
\hline Baixa otimização e insuficiência de equipamentos & & $(\mathrm{X})$ & & 45 \\
\hline $\begin{array}{c}\text { Horas apontadas incorretamente e formulário } \\
\text { dificultando esta atividade }\end{array}$ & & $(\mathrm{X})$ & & 27 \\
\hline Planejamento deficiente de uso de materiais nas \\
frentes de serviços & & $(\mathrm{X})$ & & 27 \\
\hline $\begin{array}{c}\text { Não existe um procedimento para solicitação de } \\
\text { materiais }\end{array}$ & & & (X) & 25 \\
\hline Baixa inovação metodologias de execução & & (X) & & 25 \\
\hline $\begin{array}{c}\text { Baixo índice de pesquisa e desenvolvimento de novos } \\
\text { materiais }\end{array}$ & & (X) & & 15 \\
\hline
\end{tabular}

Fonte: da autora, 2014

\subsection{Plano de ação}

Nesta etapa será elaborada a estratégia de ação em discussão com o grupo envolvido na seção de brainstorming. É importante observar que as ações serão tomadas sobre as causas fundamentais e não sobre seus efeitos. Nesse contexto deverá ser determinada a meta a ser atingida e a análise de custo de cada uma.

A ferramenta utilizada no plano de ação é o $5 \mathrm{~W} 2 \mathrm{H}$, que significa um checklist das atividades que precisam ser desenvolvidas. $\mathrm{O}$ nome desse termo se deve às primeiras letras dos nomes (em inglês) das diretrizes utilizadas neste processo. What - O que será feito. Why - Por que será feito. Where - Onde será feito. Who - Por quem será feito. How - Como será feito. How much - Quanto custará fazer. O 5W2H faz com que se busque analisar cada causa em vários níveis, sempre questionando o "porquê" até chegar à raiz do problema. 
Quadro 2 - Cronograma do Plano de ação

\begin{tabular}{|c|c|c|c|c|}
\hline Etapa & Previsto de & Previsto até & Realizado de & Realizado até \\
\hline 1 - Identificação & $11 / 3 / 2010$ & $18 / 3 / 2010$ & $18 / 3 / 2010$ & $23 / 3 / 2010$ \\
\hline 2 - Observação & $19 / 3 / 2010$ & $19 / 4 / 2010$ & $23 / 3 / 2010$ & $20 / 5 / 2010$ \\
\hline 3 - Análise & & $20 / 4 / 2010$ & $7 / 5 / 2010$ & $20 / 5 / 2010$ \\
\hline 4 - Plano de Ação & $10 / 5 / 2010$ & $24 / 5 / 2010$ & $28 / 5 / 2010$ & $29 / 9 / 2010$ \\
\hline 5 - Ação & & $22 / 6 / 2010$ & $30 / 9 / 2010$ & \\
\hline 6 - Verificação & & $1 / 9 / 2010$ & $1 / 12 / 2010$ & \\
\hline 7 - Padronização & $2 / 12 / 2010$ & $9 / 12 / 2010$ & & \\
\hline 8 - Conclusão & & $10 / 12 / 2010$ & $17 / 12 / 2010$ & \\
\hline
\end{tabular}

Fonte: da autora, 2014

\section{Quadro 3 - 5W2H Detalhamento dos projetos com informações para execução}

\begin{tabular}{|c|c|c|c|c|c|c|c|}
\hline$\overline{\text { Causas }}$ & $\overline{\text { O quê }}$ & $\overline{\text { Quem }}$ & Quando & $\overline{\text { Como }}$ & Onde & Por que & $\overline{\text { Quanto }}$ \\
\hline $\begin{array}{ll}\text { Acompanhamen- } \\
\text { to deficiente } & \text { de } \\
\text { materiais } & \text { no } \\
\text { almoxarifado } & \text { da } \\
\text { contratada. } & \end{array}$ & \begin{tabular}{|l} 
Levantar o \\
material no \\
canteiro e \\
definir a \\
quantidade \\
mínima em \\
estoque.
\end{tabular} & Técnico & 07/2009 & $\begin{array}{l}\text { Através } \\
\text { da } \\
\text { criação } \\
\text { de um } \\
\text { procedi- } \\
\text { mento de } \\
\text { controle }\end{array}$ & $\begin{array}{l}\text { No } \\
\text { canteiro } \\
\text { de } \\
\text { tercei- } \\
\text { ros }\end{array}$ & $\begin{array}{l}\text { Controle } \\
\text { atual não } \\
\text { atende }\end{array}$ & 0,00 \\
\hline $\begin{array}{ll}\text { Deficiência } & \text { no } \\
\text { planejamento } & \text { do } \\
\text { controle } & \text { dos } \\
\text { serviços } & \\
\text { programados } & \text { e } \\
\text { em execução } & \end{array}$ & $\begin{array}{l}\text { Trabalhar o } \\
\text { cronograma } \\
\text { e a } \\
\text { programa- } \\
\text { ção, de } \\
\text { serviços } \\
\text { liberadas } \\
\text { para } \\
\text { execução. }\end{array}$ & Supervisor & 08/2009 & \begin{tabular}{|l} 
Criar \\
cronogra \\
ma de \\
serviços \\
para \\
execução \\
com \\
atualiza- \\
ção \\
Semanal
\end{tabular} & $\begin{array}{l}\mathrm{Na} \\
\text { Manute } \\
\text { nção } \\
\text { çvil } \\
\text { predial }\end{array}$ & $\begin{array}{l}\text { Planeja- } \\
\text { mento } \\
\text { não } \\
\text { atende }\end{array}$ & 0,00 \\
\hline $\begin{array}{l}\text { Baixa inovação } \\
\text { nas metodologias } \\
\text { de execução }\end{array}$ & $\begin{array}{l}\text { Estimular a } \\
\text { equipe e os } \\
\text { gestores da } \\
\text { contratada a } \\
\text { pesquisar } \\
\text { em fontes } \\
\text { especializa- } \\
\text { das de } \\
\text { novos } \\
\text { métodos } \\
\text { executivos. }\end{array}$ & Supervisor & 09/2010 & $\begin{array}{l}\text { Nas } \\
\text { reuniões } \\
\text { de rotina }\end{array}$ & $\begin{array}{l}\mathrm{Na} \\
\text { Manute } \\
\text { nção } \\
\text { civil } \\
\text { predial }\end{array}$ & $\begin{array}{l}\text { Aumento } \\
\text { de } \\
\text { produtivi } \\
\text { dade e } \\
\text { melhores } \\
\text { condi- } \\
\text { ções de } \\
\text { trabalho }\end{array}$ & 0,00 \\
\hline
\end{tabular}

Fonte: da autora, 2014 


\subsection{Ação}

Durante a execução desta etapa é necessário verificar fisicamente e no local quais as ações que necessitam da ativa cooperação de todos. As reuniões participativas e as técnicas de treinamento devem ser constantes. Todas as ações e os resultados bons e ruins devem ser registrados, com o tempo em que foram previstas e realizadas.

\section{Quadro 4 - 5W2H Execução das ações}

\begin{tabular}{|c|c|c|c|c|c|c|c|}
\hline $\begin{array}{l}\text { Andamento } \\
\text { dos trabalhos }\end{array}$ & Quem & Como & $\begin{array}{c}\text { Custo } \\
\text { previsto }\end{array}$ & $\begin{array}{c}\text { Custo } \\
\text { realiza- } \\
\text { do }\end{array}$ & Previsto & Realizado & Observações \\
\hline $\begin{array}{lr}\text { Levantar } & \text { o } \\
\text { material } & \text { no } \\
\text { canteiro } & \text { e } \\
\text { definir } & \text { a } \\
\text { quantidade } & \\
\text { mínima } & \text { em } \\
\text { estoque; } \\
\text { A contratada } \\
\text { deverá repassar } \\
\text { toda sexta feira } \\
\text { à relação de } \\
\text { materiais que } \\
\text { necessitam de } \\
\text { reposição. } \\
\end{array}$ & Técnico & $\begin{array}{l}\text { Através } \\
\text { da } \\
\text { criação } \\
\text { de um } \\
\text { Procedi- } \\
\text { mento de } \\
\text { contro-le } \\
\text { de } \\
\text { Mate-rial }\end{array}$ & $\mathrm{R} \$ 0,00$ & $\mathrm{R} \$ 0,00$ & $7 / 2010$ & $7 / 2010$ & $\begin{array}{l}\text { Após análise } \\
\text { da situação } \\
\text { atual foi } \\
\text { elaborado um } \\
\text { procedimento } \\
\text { e um fluxo } \\
\text { para melhorar } \\
\text { processo de } \\
\text { requisição de } \\
\text { materiais. }\end{array}$ \\
\hline $\begin{array}{lr}\text { Informar } & \text { os } \\
\text { fatos } & \text { á } \\
\text { contratada } & \mathrm{e} \\
\text { líderes } & \mathrm{de} \\
\text { campo, } & \text { cobrar } \\
\text { ações } & \mathrm{e} \\
\text { intensificar } & \\
\text { fiscalização. } & \\
\end{array}$ & Técnico & $\begin{array}{c}\mathrm{Na} \\
\text { reunião } \\
\text { de rotina }\end{array}$ & $\mathrm{R} \$ 0,00$ & $\mathrm{R} \$ 0,00$ & $8 / 2010$ & $9 / 2010$ & $\begin{array}{l}\text { A fiscalização } \\
\text { intensificada } \\
\text { Prinicipalmen } \\
\text {-te no final do } \\
\text { dia, ou seja, a } \\
\text { chegada do } \\
\text { pessoal no } \\
\text { canteiro. }\end{array}$ \\
\hline $\begin{array}{lr}\text { Estimular } & \text { a } \\
\text { equipe e } & \text { os } \\
\text { gestores } & \text { da } \\
\text { contratada } & \text { a } \\
\text { pesquisar } & \text { em } \\
\text { fontes } & \\
\text { especializadas } \\
\text { de novos } \\
\text { métodos } \\
\text { executivos. }\end{array}$ & Supervisor & $\begin{array}{l}\mathrm{Na} \\
\text { reunião } \\
\text { de rotina }\end{array}$ & $\mathrm{R} \$ 0,00$ & $\mathrm{R} \$ 0,00$ & $8 / 2010$ & $9 / 2010$ & $\begin{array}{l}\text { Produtos } \\
\text { novos que já } \\
\text { estão sendo } \\
\text { utilizados: } \\
\text { argamassa de } \\
\text { assentamento } \\
\text { tijolos. }\end{array}$ \\
\hline
\end{tabular}

Fonte: da autora, 2014

\subsection{Verificação}

Ferramenta utilizada para itens de controle - trata-se de uma gráfica utilizada para avaliar a estabilidade, fazer um diagnóstico a fim de determinar se um processo está sobcontrole estatístico. Permite que se verifique quanto da variabilidade ocorre devido à 
variação aleatória, inerente ao próprio processo (causas comuns), e quanto é devido às ocorrências não originais ao processo (causas especiais).

\section{Figura1 - Gráfico de verificação de horas produtivas}

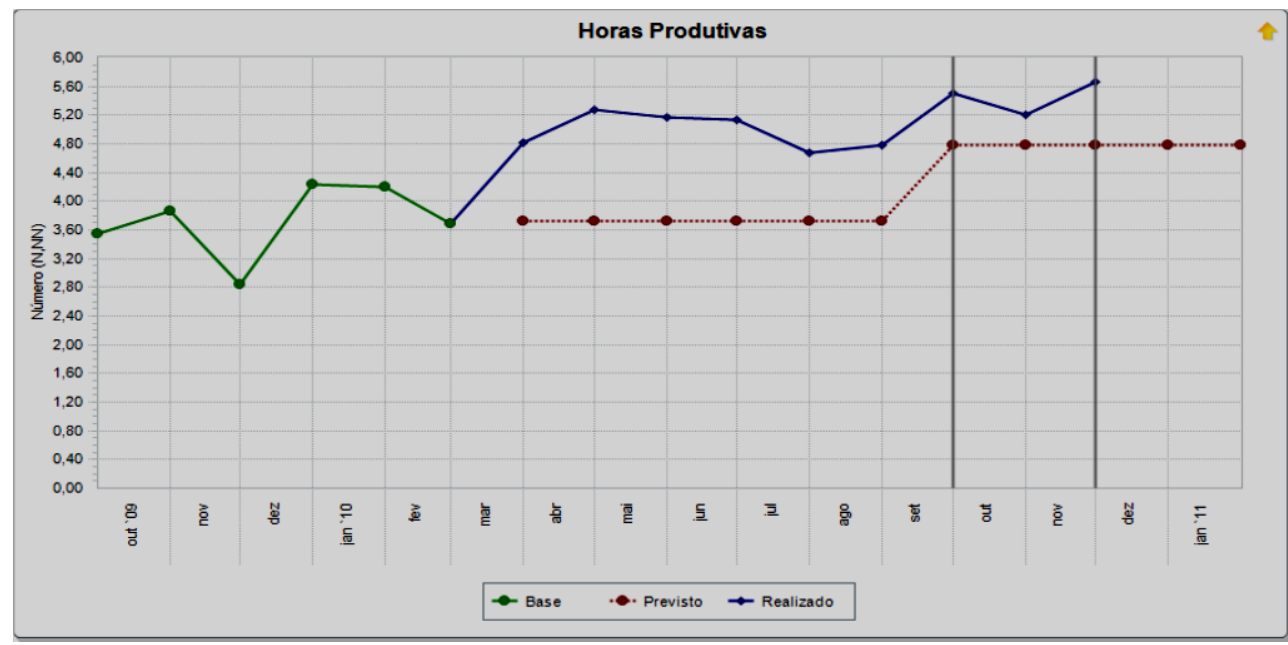

Fonte: da autora, 2014

\section{Quadro 5 - Verificação dos dados coletados e a frequência como ocorrem}

\begin{tabular}{|c|c|c|c|}
\hline Data & Base & Previsto & Realizado \\
\hline $09 / 2009$ & 3,54 & & \\
\hline $10 / 2009$ & 3,86 & & \\
\hline $11 / 2009$ & 2,85 & & \\
\hline $12 / 2009$ & 4,24 & & \\
\hline $01 / 2010$ & 4,20 & & \\
\hline $02 / 2010$ & 3,68 & & 4,81 \\
\hline $03 / 2010$ & & 3,73 & 5,28 \\
\hline $04 / 2010$ & & 3,73 & 5,17 \\
\hline $05 / 2010$ & & 3,73 & 5,13 \\
\hline $06 / 2010$ & & 3,73 & 4,67 \\
\hline $07 / 2010$ & & 3,73 & 4,79 \\
\hline $08 / 2010$ & & 3,73 & 5,50 \\
\hline $09 / 2010$ & & 4,78 & 5,21 \\
\hline $10 / 2010$ & & 4,78 & 5,67 \\
\hline $11 / 2010$ & & 4,78 & \\
\hline $12 / 2010$ & & 4,78 & \\
\hline $01 / 2011$ & & 4,78 & \\
\hline & & & \\
\hline
\end{tabular}

Fonte: da autora, 2014

\subsection{Padronização}

O principal objetivo da padronização exemplificada neste estudo através do quadro seis é esclarecer, através da ferramenta $5 \mathrm{~W} 2 \mathrm{H}$, para que servem as atividades que efetivamente devem ser incluídas ou alteradas nos padrões já existentes e garantir que os novos padrões ou que as alterações nos existentes sejam transmitidas a todos os envolvidos. 


\section{Quadro 6 - Padronização - elaboração dos documentos controlados}

\begin{tabular}{|c|c|c|c|c|c|}
\hline O Quê & Quem & Como & Previsto & Realizado & Observações \\
\hline $\begin{array}{l}\text { Elaborar padrão de } \\
\text { atendimento de } \\
\text { ordem de serviço } \\
\text { pelo contrato por } \\
\text { Administração da } \\
\text { Manutenção Civil } \\
\text { Predial. }\end{array}$ & Técnico & $\begin{array}{l}\text { Estabelecen } \\
\text { do critérios } \\
\text { que } \\
\text { orientarão a } \\
\text { forma de } \\
\text { atendimento } \\
\text { dos serviços } \\
\text { pelo } \\
\text { contrato por } \\
\text { Administra- } \\
\text { ção. } \\
\end{array}$ & $12 / 2010$ & $12 / 2010$ & $\begin{array}{l}\text { Elaborado e registrado no } \\
\text { SAP o padrão atendimento } \\
\text { serviços no contrato por } \\
\text { administração. }\end{array}$ \\
\hline $\begin{array}{l}\text { Elaborar padrão de } \\
\text { Gerenciamento de } \\
\text { Materiais }\end{array}$ & Técnico & $\begin{array}{l}\text { Estabelecen } \\
\text { do critérios } \\
\text { que vão da } \\
\text { solicitação } \\
\text { ao } \\
\text { recebimento } \\
\text { dos } \\
\text { materiais no } \\
\text { canteiro da } \\
\text { Contratada. }\end{array}$ & $12 / 2010$ & $12 / 2010$ & $\begin{array}{l}\text { Elaborado e registrado no } \\
\text { SAP o padrão } \\
\text { gerenciamento de } \\
\text { materiais (solicitação, } \\
\text { requisição e recebimento). }\end{array}$ \\
\hline $\begin{array}{l}\text { Intensificar } \\
\text { Fiscalização }\end{array}$ & Técnico & $\begin{array}{l}\text { Identifican- } \\
\text { do nas } \\
\text { frentes de } \\
\text { serviços } \\
\text { situações de } \\
\text { potencial } \\
\text { ganho de } \\
\text { horas } \\
\text { produtivas }\end{array}$ & $8 / 2010$ & $12 / 2010$ & $\begin{array}{l}\text { Esta atividade é constante } \\
\text { e deve ser realizada por } \\
\text { todos da equipe e Técnicos } \\
\text { da manutenção Civil. }\end{array}$ \\
\hline
\end{tabular}

Fonte: da autora, 2014

\section{CONCLUSÃO}

Este artigo visou apontar as possibilidades de quais as ferramentas de gestão eficiente e de qualidade podem ser adotadas para a realização de um projeto no contrato de manutenção predial. Cabe, ainda, ressaltar que a elaboração de padrões e a intensiva fiscalização exemplificada em cada etapa do projeto foi uma das formas de reduzir o back log (tempo de espera) e contribuir para o aumento da produtividade do contrato de manutenção civil predial. Entretanto, o envolvimento de toda a equipe proporcionou o maior ganho nas atividades desenvolvidas, beneficiando principalmente o crescimento técnico/profissional do setor. Este estudo demonstra um avanço significativo para a aplicação em outros contratos, sobre a complexidade de se buscar uma forma sistêmica para a manutenibilidade ${ }^{2}$ das edificações e incentivar a inovação do desenvolvimento tecnológico de produtos e serviços.

\footnotetext{
${ }^{2}$ Segundo a NBR 5.462/1994 "Manutenibilidade é a capacidade de um item ser mantido ou recolocado em condições de executar suas funções requeridas, sob condições de uso especificadas, quando a manutenção é executada sob condições determinadas e mediante procedimentos e meios prescritos.
} 
No que se refere ao uso da metodologia à ferramenta GSP é eficiente e de fácil entendimento e trabalho, conduzindo a motivação da equipe para cumprir os passos de cada etapa e assim atingir os resultados.

\section{AGRADECIMENTOS}

Agradecimentos ao Programa de Pós-graduação do Mestrado do Ambiente Construído e Patrimônio Sustentável da Escola de Arquitetura da UFMG.

\section{REFERÊNCIAS}

\section{ASSOCIAÇÃO BRASILEIRA DE NORMAS TÉCNICAS:}

NBR 5462: Confiabilidade e manutenibilidade. Reliability and main maintainability Terminology. Rio de Janeiro. 1994. 37 p.

NBR 5674: Manutenção de edificações - Requisitos para o sistema de gestão de manutenção. Building maintenance - Requirements for maintenance management. Rio de Janeiro. 2012. 25 p.

NBR 14037: Diretrizes para elaboração de manuais de uso, operação e manutenção das edificações - Requisitos para elaboração e apresentação dos conteúdos. Guidelines for building use, operation and maintenance manual preparation - Requirements for content preparation and presentation. Rio de Janeiro. 2011. $16 \mathrm{p}$.

FALCONI, Campos Vicente. Gerência da Qualidade- Total estratégia para aumentar a competitividade da empresa brasileira. Belo Horizonte: Fundação Christiano Ottoni/ Escola de Engenharia da UFMG, 1990.

FALCONI, Campos Vicente. Gerenciamento da rotina do trabalho do dia-a-dia. Belo Horizonte: Fundação Christiano Ottoni/ Escola de Engenharia da UFMG, 1990.

XENOS, Harilaus G. Gerenciando a Manutenção Produtiva, Belo Horizonte: editora de desenvolvimento gerência, 1998.

CHIU, H-N. \& HUANG, B.S. The economic design of $\mathrm{x}$ control charts under a preventive maintenance policy. International Journal of Quality \& Reliability Management, Cambridge, 13 (1): 61-71, 1996. REVISTA DE CIÊNCIA \& TECNOLOGIA • V. 11, No 22 pp. 35-42. Acesso em 24/04/2014.

ISHIKAMA, Kaoru. Quality control circles at work: cases from Japan's manufacturing and service sectors: editor - Asian productivity organization. 1984. 232 p.

ISHIKAMA, Kaoru. Guide to quality control. Series: industrial engineering \& technology. 2 ed. Quality Resources.1986. 226 p. 